\title{
Cerebral Dural Arteriovenous Fistulas-an Update on Pathophysiology, Natural History and Treatment
}

\author{
Bradley A Gross, Brian T Jankowitz, Robert M Friedlander \\ Department of Neurological Surgery, University of Pittsburgh Medical Center, Pittsburgh, Pennsylvania, US
}

DOI: https://doi.org/10.17925/USN.2017.13.01.47

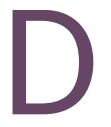

ural arteriovenous fistulas are unique vascular shunts that can be discovered incidentally or after presentation with pulsatile tinnitus, ocular symptoms, focal neurologic deficits, and even hemorrhage. Their natural history is predicated on the shunt's venous drainage pattern; presentation modality and venous ectasia are also independent factors influencing lesion natural history. Their management is often via endovascular embolization; surgical disconnection of high risk fistulas and radiosurgery for low risk shunts unamenable to embolization are also options. This article will provide a modern update on dural arteriovenous fistula pathophysiology, natural history and treatment approaches.

\section{Keywords}

Arteriovenous fistula, dAVF, dural arteriovenous fistula, embolization, microsurgery, radiosurgery, hemorrhage

Disclosure: Bradley A Gross, Brian T Jankowitz, and Robert $\mathrm{M}$ Friedlander have nothing to disclose in relation to this article. No funding was received for the publication of this article.

Compliance with Ethics: This study involves a review of the literature and did not involve any studies with human or animal subjects performed by any of the authors.

Authorship: All named authors meet the International Committee of Medical Journal Editors (ICMJE) criteria for authorship of this manuscript, take responsibility for the integrity of the work as a whole, and have given final approval to the version to be published.

open Access: This article is published under the Creative Commons Attribution Noncommercial License, which permits any noncommercial use, distribution, adaptation, and reproduction provided the original author(s) and source are given appropriate credit.

Received: December 8, 2016

Accepted: January 13, 2017

Citation: US Neurology, 2017;13(1):47-9

Corresponding Author: Bradley A Gross, Department of Neurological Surgery, University of Pittsburgh, Suite B-400 200 Lothrop St., Pittsburgh, Pennsylvania, US 15213.

E: grossb2@upmc.edu
Dural arteriovenous fistulas (dAVF)s are unique to the neuraxis as the arteriovenous shunt site is contained within the dural leaflets. They may be discovered incidentally or in a workup of a variety of potential neurological sequelae, including pulsatile tinnitus, ocular symptoms, focal neurologic deficits as a result of venous hypertension or even intracranial hemorrhage. ${ }^{1-7}$ Symptoms of venous hypertension may also include seizures, dementia, or even Parkinsonism which can make it initially challenging to suspect a dAVF as the underlying cause. ${ }^{4,7-10}$

The majority of dAVFs are discovered in patients between their fifth and seventh decades of life; ${ }^{5,7,11-15}$ rarely "adult-type" dAVFs may be diagnosed in children. ${ }^{16}$ There is an overall male sex predilection among these patients with the exception of the subset of cavernous sinus dAVFs that are more commonly found in women. ${ }^{7.11-13}$ While the majority of dAVFs are idiopathic, a known subset can develop following trauma; in one series of 260 cases, $7 \%$ occurred after trauma. ${ }^{11}$ Their arterial supply is comprised of meningeal arteries; dependent on the location of the shunt, the most common vessel supplying these fistulas is generally the middle meningeal artery.11 The occipital artery is often involved as well, particularly when considering posterior fossa and transverse/sigmoid fistulas. Drainage can be into a venous sinus, meningeal vein or subarachnoid vein. The most common dAVF location is along the transverse and/or sigmoid sinus, and the majority of these fistulas present with pulsatile

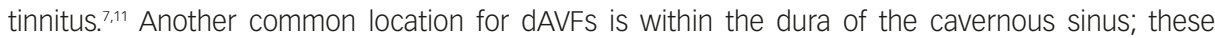
fistulas may present with ocular symptoms such as chemosis, proptosis and ophthalmoparesis. ${ }^{711,17-19}$ Via reflux into the cavernous sinus, marginal sinus dAVFs, also known as foramen magnum, hypoglossal canal and condylar dAVFs may also present with ocular symptoms. ${ }^{1,20}$ Fistulas along the cribriform plate ("ethmoidal"), convexity or tentorium may remain silent until presenting with symptoms of venous hypertension and/or hemorrhage. ${ }^{4,5,7,11-13}$

\section{Natural history}

The natural history of dAVFs should address the untreated course of associated symptomatology such as pulsatile tinnitus or ocular symptoms along with the risk of developing venous hypertension and/or hemorrhage. Although the latter has been studied, the natural course of pulsatile tinnitus or ocular symptoms that result from these fistulas is less well evaluated in the literature to date. While the course of pulsatile tinnitus attributable to the fistula may be difficult to predict, most practitioners espouse a naturally unrelenting and worsening course of ocular symptoms that initially develop secondary to a dAVF.

Houser et al. first emphasized the importance of drainage into leptomeningeal veins as a risk factor for an "aggressive course." ${ }^{2}$ This specifically referred to the risk of developing symptomatic venous 
Table 1: dAVF classification schemes as defined by venous drainage

\begin{tabular}{|l|l|l|l|}
\hline Type & $\begin{array}{l}\text { Djindjian-Merland } \\
1978^{22}\end{array}$ & $\begin{array}{l}\text { Borden-Schucart } \\
1995^{23}\end{array}$ & Cognard-Merland $1995^{24}$ \\
\hline I & Sinus & Sinus & Antegrade through sinus \\
\hline II & Sinus with LVR & Sinus with LVR & $\begin{array}{l}\text { Ila: sinus, retrograde flow } \\
\text { Ilb: sinus with LVR } \\
\text { Ila+b: combination }\end{array}$ \\
\hline III & Direct LVD & Direct LVD & Direct LVD \\
\hline IV & Direct LVD with ectasia & & Direct LVD with ectasia \\
\hline V & & & $\begin{array}{l}\text { Spinal perimedullary } \\
\text { drainage }\end{array}$ \\
\hline
\end{tabular}

dAVF = dural arteriovenous fistulas; $L$ LV = leptomeningeal venous drainage; $L V R=$ leptomeningeal venous reflux.

hypertension and/or hemorrhage. The presence or absence of drainage into leptomeningeal veins defines the modern dichotomy of "high risk" and "Iow risk" dAVFs, respectively. Low risk fistulas can only serve as a source of neurological morbidity as a result of pulsatile tinnitus or ocular symptoms. They do not pose a risk of intracerebral venous hypertension or hemorrhage unless they develop leptomeningeal venous drainage; ${ }^{21}$ in one analysis, this only occurred in $1.4 \%$ of low risk fistulas. ${ }^{7}$ These dAVFs typically occur along the transverse/sigmoid sinus, cavernous sinus or marginal sinus, and of note, up to $13 \%$ may spontaneously thrombose over time..$^{7,11,21}$

"High risk" dAVFs are more often diagnosed in men. ${ }^{7.11-13}$ These fistulas pose a risk of symptomatic venous hypertension resulting in nonhemorrhagic neurological deficits (NHND) or frank intracranial hemorrhage. In one study, the annual rates of NHND and hemorrhage for these dAVFs were $4 \%$ and $6 \%$, respectively. ${ }^{7}$ Modern reports have additionally found that high risk dAVFs presenting with NHND or hemorrhage have an independently greater subsequent annual rate of hemorrhage, ${ }^{7,14}$ in one study these rates were $10 \%$ and $46 \%$, respectively. In addition, venous ectasia has also been found to be an independent risk factor for a more aggressive course, ${ }^{7,12}$ with one study citing an annual hemorrhage rate of $21 \%$ for this subgroup of high risk dAVFs. ${ }^{\text {? }}$

Multiple dAVF classification schemes have been proposed to facilitate natural history risk stratification. Their foundation is the original four type scheme proposed by Djindjian that has largely withstood the test of time (Table 1).22 "Low risk" dAVFs are Type I. dAVFs that drain into a venous sinus with reflux into leptomeningeal veins are Type I. Those that drain directly into leptomeningeal veins are Type III; Type IV dAVFs drain directly into ectatic leptomeningeal veins. Twenty years after this scheme was proposed, Borden, Wu and Schucart attempted to extrapolate it to spinal lesions and excluded the Type IV fistula. ${ }^{23}$ In light of modern natural history studies, it is prudent to keep this unique designation to connote a greater risk of hemorrhage for those with ectatic venous drainage. Djindjian's pupil, Merland, along with Cognard, further extended the Djindjian classification into five dAVF types (Table 1). ${ }^{24}$

\section{Treatment}

Given the malignant natural history of "high risk" dAVFs, treatment is indicated for all of these lesions. Asymptomatic Type I/"low risk" fistulas should be observed along with those associated with tolerable pulsatile tinnitus. Those causing ocular symptoms are generally considered for treatment.

dAVFs can be treated by direct occlusion at the fistula site. This treatment tenet lends itself to endovascular approaches that can attack the shunt site via either arterial or venous access. As such, endovascular embolization with permanent embolisates such as n-butylcyanoacrylate (NBCA) or Onyx serves as the mainstay of modern dAVF treatment.

\section{Endovascular}

Embolization is typically performed under general anesthesia. Transarterial conduits to the fistula site, ideally via the middle meningeal artery, are sought on a diagnostic angiogram. High risk fistulas along the convexity and select tentorial and transverse-sigmoid fistulas can often be superselectively accessed via a middle meningeal artery pedicle for transarterial embolization. While NBCA is a traditional permanent embolisate that has been used with success, ${ }^{25}$ the easy "pushability" of Onyx makes it the modern mainstay for transarterial embolization of dAVFS. ${ }^{11,26-30}$ Multiple series have illustrated the advantageous impact of Onyx on dAVF angiographic occlusion rates and the ability to effectively treat dAVFs via fewer arterial pedicles. ${ }^{11,26,29}$ Many cavernous dAVFs are approached transvenously and can be managed with coil embolization with or without adjunctive Onyx. ${ }^{11,17}$

The overall goal of treatment is thorough casting of the shunt site and proximal draining vein with embolisate. Transarterial occlusion without adequate penetration of the shunt site and proximal draining vein may result in initial angiographic nonopacification of the fistula; however the risk of angiographic recurrence is considerable. ${ }^{11,31,32}$ This is an important consideration when selecting a transarterial route to the fistula site. Penetration is generally more facile via the middle meningeal artery as compared to the occipital artery. Occipital artery pedicles can often be inviting; however penetration of the fistula by an embolic agent that must travel transosseously can meet with more difficulty. Notwithstanding poor shunt site penetration, in one series, the risk of recurrence was $3 \% .{ }^{11}$

Overall clinical and angiographic results for embolization are excellent for well selected fistulas. In one series of 260 cases treated endovascularly, "80\%" was a good predictor for 1 ) angiographic obliteration of non-ethmoidal fistulas in the Onyx era, 2) the rate of clinical improvement/resolution of pulsatile tinnitus when present, and 3) the rate of clinical improvement/ resolution of ocular symptoms when present. ${ }^{11}$ In this series, the overall complication rate was $8 \%$; permanent neurological complications were observed in $3 \%$ of cases. Very similar results have been reproduced in other series in the Onyx era as well. ${ }^{29,30}$

\section{Surgical disconnection}

High risk fistulas whose shunt sites cannot be occluded by endovascular means can be treated by identifying the draining leptomeningeal vein exiting the dura and disconnecting it surgically. ${ }^{33-38}$ This often includes ethmoidal fistulas that cannot be safely accessed via the ophthalmic artery without considerable risk to vision as well as tentorial/petrosal fistulas lacking an adequate caliber transarterial conduit. ${ }^{38,39}$ Fortunately, these two fistula types are relatively facile surgical targets. In one study of 20 patients with high risk dAVFs undergoing surgical disconnection, angiographic cure was achieved in all cases with a morbidity/mortality rate of $10 \% .{ }^{35}$ In particular, surgical results for ethmoidal fistulas are excellent, with high obliteration rates (99-100\%) and low morbidity (1-2\%). ${ }^{39-41}$ 


\section{Radiosurgery}

Low risk fistulas with tolerable symptoms or those that cannot be occluded endovascularly may be treated with radiosurgery. Akin to arteriovenous malformation radiosurgery, a latency period is required prior to a potential clinical and angiographic impact of treatment. Early, adjunctive partial embolization after radiosurgery may be considered to hasten the rate of clinical improvement. ${ }^{42,43}$

Case series of radiosurgical treatment have accumulated over the past 25 years. ${ }^{42-48} \mathrm{~A}$ recent systematic review amalgamating results across these series reported an overall obliteration rate of $71 \%{ }^{49}$ Transient deterioration was observed in $9.1 \%$ of patients with permanent morbidity in $2.4 \%$ of patients. Interestingly, obliteration rates were highest for cavernous sinus dAVFs (84\%) and those without leptomeningeal venous drainage (80\%). ${ }^{49}$

\section{Conclusion}

dAVFS can manifest across a panoply of potential presentation modalities. Their natural history is largely based on venous drainage. dAVFs with leptomeningeal venous drainage are ubiquitously considered for treatment given the prospective risk of symptomatic venous hypertension and/ or intracranial hemorrhage. Those without these high risk features are observed unless symptoms are intolerable. Endovascular treatment is first line for these lesions. Surgical disconnection is considered for high risk dAVFs without an endovascularly-accessible fistula point. Radiosurgery is a consideration for low risk lesions that cannot be accessed endovascularly. $\square$
1. Newton $\mathrm{TH}$, Cronqvist $\mathrm{S}$, Involvement of dural arteries in intracranial arteriovenous malformations, Radiology, 1969;93:1071-8.

2. Houser OW, Baker HL Jr, Rhoton AL Jr, et al., Intracranial dural arteriovenous malformations, Radiology, 1972;105:55-64.

3. Malik GM, Pearce JE, Ausman JI, et al., Dural arteriovenous malformations and intracranial hemorrhage, Neurosurgery, 1984;15:332-9.

4. Lasjaunias P, Chiu M, ter Brugge K, et al., Neurological manifestations of intracranial dural arteriovenous malformations, J Neurosurg, 1986;64:724-30.

5. Awad IA, Little JR, Akarawi WP, et al., Intracranial dural arteriovenous malformations: Factors predisposing to an aggressive neurological course, J Neurosurg, 1990;72:839-50

6. Brown RD, Jr., Wiebers DO, Nichols DA, Intracranial dural arteriovenous fistulae: angiographic predictors of intracranial hemorrhage and clinical outcome in nonsurgical patients, INeurosurg, 1994:81:531-8.

7. Gross BA, Du R, The natural history of cerebral dura arteriovenous fistulae, Neurosurgery, 2012;71:594-602.

8. Hurst RW, Bagley $L J$, Galetta S, et al., Dementia resulting from dural arteriovenous fistulas: the pathologic findings of venous hypertensive encephalopathy, AJNR Am J Neuroradiol, 1998;19:1267-73.

9. Holekamp TF, Mollman ME, Murphy RK, et al., Dural arteriovenous fistula-induced thalamic dementia: report of 4 cases, J Neurosurg 124:1752-65.

10. Nogueira RG, Baccin CE, Rabinov JD, et al., Reversible parkinsonism after treatment of dural arteriovenous fistula J Neuroimaging, 2009;19:183-4.

11. Gross BA, Albuquerque FC, Moon $\mathrm{K}$, et al., Evolution of treatment and a detailed analysis of occlusion, recurrence, and clinical outcomes in an endovascular library of 260 dural arteriovenous fistulas, J Neurosurg, 2016; epub ahead of print Sep 2,2016.

12. Bulters DO, Mathad N, Culliford $D$, et al., The natural history of cranial dural arteriovenous fistulae with cortical venous reflux - the significance of venous ectasia, Neurosurgery, 2012;70:312-8

13. Soderman M, Pavic L, Edner G, et al., Natural history of dural arteriovenous shunts, Stroke, 2008:39:1735-9.

14. Strom RG, Botros JA, Refai $D$, et al., Cranial dural arteriovenous fistulae: asymptomatic cortical venous drainage portends less aggressive clinical course, Neurosurgery, 2009;64: 241-8.

15. van Dijk JM, ter Brugge KG, Willinsky RA, et al., Clinical course of cranial dural arteriovenous fistulas with long-term persistent cortical venous reflux, Stroke, 2002;33:1233-6.

16. Gross BA, Akgoz A, Orbach DB. Dural arteriovenous shunts in children, J Ped Neuroradiol, 2013:2:263-8.

17. Ducruet $\mathrm{AF}$, Albuquerque $\mathrm{FC}$, Crowley RW, et al., The evolution of endovascular treatment of carotid cavernous fistulas: a singlecenter experience, World Neurosurg, 2013;80:538-48.
18. Elhammady MS, Wolfe $S Q$ Farhat $H$, et al, Onyx embolization of carotid-cavernous fistulas, J Neurosurg, 2010;112:589-94.

19. Meyers PM, Halbach W, Dowd CF, et al., Dural carotid cavernous fistula: definitive endovascular management and long-term follow-up, Am J Ophthalmol, 2002;134:85-92.

20. McDougall $C G$, Halbach W, Dowd CF, et al.: Dural arteriovenous fistulas of the marginal sinus, AJNR Am I Neuroradiol, 1997:18:1565-72

21. Satomi J, van Dijk JM, Terbrugge KG, et al., Benign cranial dura arteriovenous fistulas: outcome of conservative management based on the natural history of the lesion, J Neurosurg, 2002;97:767-70.

22. Djindjian R, Merland JJ, Super-Selective Arteriography of the External Carotid Artery Springer-Verlag, Springer Berlin Heidelberg, Germany, 1978.

23. Borden JA, Wu JK, Shucart WA, A proposed classification for spinal and cranial dural arteriovenous fistulous malformations and implications for treatment, I Neurosurg , 1995;82:166-79.

24. Cognard C, Gobin YP, Pierot L, et al., Cerebral dural arteriovenous fistulas: clinical and angiographic correlation with a revised classification of venous drainage, Radiology, 1995;194:671-80

25. Baltsavias $G$, Valavanis A, Endovascular treatment of 170 consecutive cranial dural Arteriovenous fistulas: results and complications, Neurosurg Rev, 2014:37:63-71.

26. Macdonald JH, Millar JS, Barker CS, Endovascular treatment of cranial dural arteriovenous fistulas: a single-centre, 14year experience and the impact of Onyx on local practise, Neuroradiology, 2010;52:387-95

27. van Rooij WJ, Sluzewski M, Curative embolization with Onyx of dural arteriovenous fistulas with cortical venous drainage, AJNR Am J Neuroradiol, 2010:31:1516-20.

28. Natarajan SK, Ghodke B, Kim $\sqcup$, et al. Multimodality treatment of intracranial dural arteriovenous fistulas in the Onyx era: a single center experience, World Neurosurg, 2010;73:365-79.

29. Rabinov JD, Yoo AJ, Ogilvy CS, et al., ONYX versus n-BCA for embolization of cranial dural arteriovenous fistulas, I Neurointer Surg, 2013;5:306-10.

30. Rangel-Castilla L, Barber SM, Klucznik R, et al., Mid and long term outcomes of dural arteriovenous fistula endovascular management with Onyx. Experience of a single tertiary center J Neurointerv Surg, 2014;6:607-13.

31. Ambekar S, Gaynor BG, Peterson EC, et al., Long-term angiographic results of endovascularly "cured" intracranial dural arteriovenous fistulas, J Neurosurg, 2016;124:1123-7.

32. Chandra RV, Leslie-Mazwi TM, Mehta BP, et al., Transarterial onyx embolization of cranial dural arteriovenous fistulas: long-term follow-up, AJNR Am I Neuroradiol, 2014:35:1793-7.

33. Gross BA, Du R, Surgical treatment of high grade dural arteriovenous fistulae, J Clin Neurosci, 2013:20:1527-32.
34. Liu JK, Dogan A, Ellegala DB, et al., The role of surgery for highgrade intracranial dural arteriovenous fistulas: importance of obliteration of venous outflow, J Neurosurg, 2009:110:913-20.

35. Collice M, D'Aliberti G, Talamonti G, et al., Surgical interruption of leptomeningeal drainage as treatment for intracranial dural arteriovenous fistulas without dural sinus drainage, I Neurosurg, 1996:84:810-7.

36. Thompson BG, Doppman JL, Oldfield EH. Treatment of cranial dural arteriovenous fistulae by interruption of leptomeningeal venous drainage, J Neurosurg, 1994;80:617-23.

37. Al-Mahfoudh R, Kirollos R, Mitchell P, et al., Surgical disconnection of the cortical venous reflux for high-grade intracranial dural arteriovenous fistulas, World Neurosurg, 2015;83:652-6.

38. Kakarla UK, Deshmukh VR, Zabramski JM, et al., Surgical treatment of high-risk intracranial dural arteriovenous fistulae: clinical outcomes and avoidance of complications, Neurosurgery, 2007:61:447-59.

39. Gross BA, Moon K, Kalani MY, et al., Clinical and anatomic insights from a series of ethmoidal dural arteriovenous fistulas at the Barrow Neurological Institute, World Neurosurg, 2016;93:94-99.

40. Lawton MT, Chun J, Wilson CB, et al., Ethmoidal dural arteriovenous fistulae: an assessment of surgical and endovascular management, Neurosurgery, 1999:45:805-10.

41. Martin NA, King WA, Wilson CB, et al., Management of dural arteriovenous malformations of the anterior cranial fossa I Neurosurg, 1990;72:692-7.

42. Pollock BE, Nichols DA, Garrity JA, et al., Stereotactic radiosurgery and particulate embolization for cavernous sinus dural arteriovenous fistulae, Neurosurgery, 1999;45:459-66.

43. Yang $\mathrm{H}$, Kano $\mathrm{H}$, Kondziolka D, et al., Stereotactic radiosurgery with or without embolization for intracranial dural arteriovenous fistulae, Neurosurgery, 2010;67:1276-85.

44. Barcia-Salorio IL, Soler F, Hernandez G, et al., Radiosurgica treatment of low flow carotid-cavernous fistulae, Acta Neurochir Supp/ (Wien), 1991;52:93-5.

45. Cifarelli CP, Kaptain G, Yen C, et al., Gamma knife radiosurgery for dural arteriovenous fistulae, Neurosurgery, 2010;67:1230-5.

46. Friedman JA, Pollock BE, Nichols DA, et al., Results of combined stereotactic radiosurgery and transarterial embolization of dural arteriovenous fistulae of the transverse and sigmoid sinuses, J Neurosurg, 2001:94:886-91.

47. Jung $\mathrm{HH}$, Chang JH, Whang $\mathrm{K}$, et al., Gamma knife surgery for lowflow cavernous sinus dural arteriovenous fistulae, J Neurosurg, 2010;113:21-7.

48. Soderman M, Edner G, Ericson K, et al., Gamma knife surgery for dural arteriovenous shunts: 25 years of experience, J Neurosurg. 2006;104:867-75.

49. Gross BA, Ropper AE, Popp AJ, et al., Stereotactic radiosurgery for cerebral dural arteriovenous fistulas, Neurosurg Focus, 2012;32:E18. 